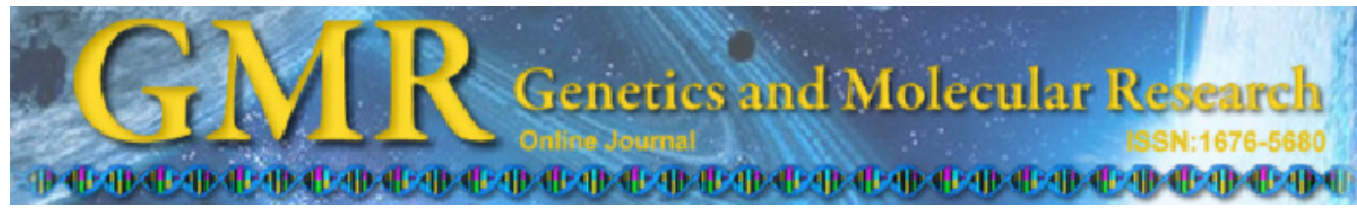

\title{
Relationships between four measures of genetic distance and breeding behavior in spring wheat
}

\author{
G. Benin ${ }^{1}$, G. Matei ${ }^{1}$, A. Costa de Oliveira ${ }^{2}$, G.O. Silva ${ }^{3}$, T.R. Hagemann ${ }^{2}$, \\ C. Lemes da Silva ${ }^{1}$, E.S. Pagliosa ${ }^{1}$ and E. Beche ${ }^{1}$ \\ ${ }^{1}$ Programa de Pós-Graduação em Agronomia, \\ Universidade Tecnológica Federal do Paraná, Pato Branco, PR, Brasil \\ ${ }^{2}$ Centro de Genômica e Fitomelhoramento, \\ Universidade Federal de Pelotas, Pelotas, RS, Brasil \\ ${ }^{3}$ EMBRAPA, Canoinhas, SC, Brasil \\ Corresponding author: G. Benin \\ E-mail: benin@utfpr.edu.br
}

Genet. Mol. Res. 11 (3): 2390-2400 (2012)

Received January 24, 2012

Accepted May 2, 2012

Published June 15, 2012

DOI http://dx.doi.org/10.4238/2012.June.15.3

\begin{abstract}
We estimated the genetic distances among 10 spring wheat genotypes based on pedigree data, morphological traits and AFLP markers, used individually and combined with morphological traits, to find the best predictors of general- and specific-combining abilities among parental genotypes. Ten wheat parents were crossed in a diallel form, disregarding reciprocal hybrids, totaling 45 combinations. The $F_{1}$ hybrids, $F_{2}$ populations and parents were evaluated in the field in 2007. The experimental plots consisted of 20 plants for $F_{1}$ hybrids and 40 plants for parental and $F_{2}$ populations. All methods (pedigree data, AFLP markers and morphological traits, used individually and combined) were found to be useful for the assessment of genetic diversity. The significant coefficient correlations ranged from low $(0.45)$ to moderate $(0.67)$ between the distance measures and hybrid performance. There was significant agreement between the distance measures based on AFLP markers $v s$ morphological traits + AFLP markers $(\mathrm{r}=0.47)$ and between pedigree data $v s$ morphological traits
\end{abstract}


+ AFLP markers $(\mathrm{r}=0.43)$. The pedigree distance was positively associated with traits 100-kernel weight and grain yield per plant in $\mathrm{F}_{1}$ (correlations of 0.67 and 0.62 , respectively) and $\mathrm{F}_{2}$ (correlations of 0.62 and 0.59 , respectively) generations. These correlation values indicate that the genetic distance, based on pedigree data, could replace diallel crosses for the selection of parents with higher combining ability and with moderate reliability.

Key words: Genetic dissimilarity; Selection of parents; Diallel analysis

\section{INTRODUCTION}

Parental selection is the major step in the development of new cultivars. Efficient identification of superior hybrid combinations is a fundamental issue in wheat breeding programs (Gowda et al., 2010). If superior crosses could be predicted before field evaluation, the efficiency of hybrid breeding programs could be greatly enhanced. The combination of molecular techniques and biometrical methods has allowed the development of novel ways for evaluating genetic variability. Among the methods used for quantifying genetic distance are morphological (syn. Phenotypic) traits (Yadav et al., 2007) and molecular markers as well as pedigree information (Paczos-Grzeda, 2004; Dreisigacker et al., 2005).

The precision of genetic variation estimates depends on the method used. The comparison of different methods for estimating genetic diversity could define their usefulness in plant breeding (Almanza-Pinzón et al., 2003). Molecular markers have the advantage of providing genome assessments that are not influenced by the $\mathrm{G} \times \mathrm{E}$ interactions and are not limited in number, as is true for morphological data (Máric et al., 2004). Molecular markers with a high multiplex index, such as amplified fragment length polymorphism (AFLP), allow precise assessment and robust essay results. However, this assessment covers the entire genome and is not limited to the regions associated with target traits. Therefore, the combined used of morphological and molecular markers allows a more representative sampling of the genome (Franco et al., 1997; Mohammadi and Prasanna, 2003). Besides facilitating the study of diversity, coefficients of parentage analysis can indicate cultivars that are less likely to possess similar genes (May et al., 1995); however, this analysis may over- or under-estimate genetic similarity between cultivars.

Although a variety of methods for estimating genetic similarity are available, only a few studies have examined the relationships between them. Moreover, some of the results obtained from various researches are unclear with respect to the relationship between distance studies and hybrid performance (Krystkowiak et al., 2009; Crossa et al., 2010).

The objectives of this study were to investigate the relationships between genetic distance estimates obtained using different methods (by using morphological markers, pedigree data, AFLP, and morphological markers plus AFLP) and their associations with wheat hybrid performance for various quantitative traits.

\section{MATERIAL AND METHODS}

A field experiment was carried out in Pato Branco-PR (26'10' S; 52'41'W and 743 
m), and the soil at the Station was of the Hapludox type. Parents used in this study are shown in Table 1. These genotypes were chosen on the basis of their yield potential and agronomical traits. In 2006, the parents were crossed in complete diallel mating design, without reciprocals, in a total of 45 hybrid combinations. In the same year, a sample of $F_{1}$ seeds from each cross was sown in the greenhouse for obtaining the $\mathrm{F}_{2}$ generation. Reminiscent seeds were maintained under controlled conditions.

\begin{tabular}{|c|c|c|}
\hline Parents & Pedigree & Release year \\
\hline Abalone & ORL93299/3/ORL92171//EMB16/2/OR1/4/Rubi & 2006 \\
\hline Pampeano & ORL91274/ORL93807//ORL95711 & 2004 \\
\hline BRS Timbaúva & BR 32/Embrapa 27 & 2002 \\
\hline BRS Guamirim & EMB 27/Buck Nandu//PF 93159 & 2005 \\
\hline BRS Figueira & Cooker 762/2/CNT 8 & 2003 \\
\hline BRS Louro & PF 869114/BR 23 & 2002 \\
\hline CD 115 & PF 89232/OC 938 & 2001 \\
\hline Fundacep 50 & CEP 88132/PG 876//BR 34/CRDN & 2004 \\
\hline BRS 208 & CPAC 89118/3/BR 23//CEP 19/PF 85490 & 2004 \\
\hline UTF 0605 & OR 1/Embrapa 16 & - \\
\hline
\end{tabular}

In 2007, the $\mathrm{F}_{1}$ hybrids, $\mathrm{F}_{2}$ populations, and parents were planted in a complete random design with 3 replications. The experimental plots consisted of 20 plants for $\mathrm{F}_{1}$ hybrids, and 40 plants for parental and $\mathrm{F}_{2}$ populations. There was a $30-\mathrm{cm}$ spacing between plants and between rows. The field management included the following: fertilization with $250 \mathrm{~kg} / \mathrm{ha}$ NPK (8-20-20) and additional $50 \mathrm{~kg} / \mathrm{ha}$ nitrogen at the beginning of tillering, weed control, pesticide application, and disease control. The remaining crop practices were in accordance to the recommendations for the wheat crop.

The following morphological traits were evaluated: plant height obtained by measuring culm length $(\mathrm{cm})$ from the soil surface up to the tip of the flower, excluding awns; spikes per plant obtained by individually counting the spikes of each plant; kernels per spike (KS) obtained by counting the total number of kernels of each plant and dividing by the number of spikes, 100-kernel weight (100-KW) in grams; grain yield per plant (GYP) obtained by measuring the grain yield of individually threshed plants, in grams.

The morphological data were subjected to individual and general variance analyses. Later, the square sum of treatments were classified as general (GCA) and specific (SCA) combining ability. Method 2 and model B of Griffing (1956) was applied using the statistical model:

$$
Y i j=m+g i+g j+s i j+\varepsilon i j
$$

where $Y i j$ is the combination $(i \neq j)$ or parental $(i=j)$ mean value; $m$ is the general mean; $g i, g j$ are the general combining ability effects of the $i$-th and $j$-th parent, respectively; sij is the effect of the specific combining ability for the crosses among the parents $i$ and $j$; and $\varepsilon i j$ is the average experimental error. These analyses as well as the calculation of the generalized distance of Mahalanobis $\left(\mathrm{D}^{2}\right)$ between all parents were performed using the Genes software (Cruz, 2006). For obtaining AFLP markers, 5 primer combinations were used (M-CAG/E-ACC, 
M-CTT/E-AGC, M-CAG/E-AGC, M-CTT/E-ACG, M-CTT/E-AGG, where E: EcoRI and $M$ : $M s e I)$. In order to visualize the fragments, amplification products were separated by electrophoresis on denaturing polyacrylamide gels $(6 \%)$ and silver stained.

The data were converted to binary data points (1/0) according to the presence or absence of fragments. An estimation of genetic similarity was obtained using Dice's similarity coefficient by using the NTSYS pc 2.1 software (Rohlf, 2000). The following equation was used:

$$
S i j=2 N i j /(N i+N j)
$$

where $N i j=$ number of common bands in $i$ and $j$; Ni= number of bands present in genotype $i$, and $N j=$ number of bands present in genotype $j$.

Genetic similarity obtained using combined morphological and AFLP markers was analyzed using the complement of Gower's similarity (Gower, 1971), index by using the MULTIV v. 2.3 software (Pillar, 1997). This method converts the distance for quantitative traits to a specific value on a scale of 0 to 1 ; this, in turn, allows the simultaneous use of both quantitative and qualitative data in generating a distance matrix (Franco et al., 1997). Inbreeding coefficients were estimated using Malécot's coefficient with pedigrees from Table 1 by using the SAS program (SAS Institute, 2002).

Similarity matrices obtained from morphological traits, AFLP markers, combined marker analysis (morphological and molecular), and inbreeding coefficient complement were transformed to genetic dissimilarity matrices according to the following equation:

$$
D i j=1-S i j
$$

(Equation 3)

where $D i j=$ genetic dissimilarity between each parental pair $i$ and $j$; Sij = genetic similarity between each parental pair $i$ and $j$. On the basis of the dissimilarity matrix generated, a dendrogram was built by using an average distance clustering analysis (UPGMA), and the cophenetic correlation coefficient was estimated using the same software described for morphological data.

Four dendrograms were built using the UPGMA method based on the dissimilarity matrices. The fitting between dissimilarity matrices and dendrograms was estimated using the cophenetic correlation coefficient (r), according to Sokal and Rohlf (1962). The estimate of correlation (association) between the distance matrices obtained using morphological, molecular, pedigree, and combined morphological and molecular methods was obtained using the Mantel's test of matrix comparisons, with 1000 permutations. All analyses were performed using the NTSYS pc 2.1 software (Rohlf, 2000). However, the association between genetic distance measures and the combining ability of parents involved in the crosses for different traits and generation and sowing methods used in the study were estimated according to Pearson correlation.

\section{RESULTS AND DISCUSSION}

Analysis of variance based on the diallel model showed differences for all the tested morphological traits (Table 2). This confirmed that the selected parents and their respective hybrid combinations were contrasting. No significant differences were detected for generations, as has been reported by Bertan et al. (2009). However, the generation effect showed 
interactions with treatment and with GCA and SCA. Therefore, the inferences concerning combining abilities were individually derived on the basis of the analysis of generations $\left(\mathrm{F}_{1}\right.$ and $\mathrm{F}_{2}$ ), where the evaluated treatments indicated differences for all traits. In addition, GCA and SCA values revealed differences between the populations (Table 2).

Table 2. Mean squares from the diallel variance analysis of $F_{1}$ and $F_{2}$ generations for five phenotypic wheat traits, analyzed by the diallel analysis model proposed by Griffing (1956).

\begin{tabular}{|c|c|c|c|c|c|c|}
\hline \multirow[t]{2}{*}{ Sources of variation } & \multirow[t]{2}{*}{ d.f. } & \multicolumn{5}{|c|}{ Traits/Mean squares } \\
\hline & & PH & SP & KS & $100-\mathrm{KW}$ & GYP \\
\hline \multicolumn{7}{|c|}{ Combined analysis of parents and $\mathrm{F}_{1}$ and $\mathrm{F}_{2}$ hybrid combinations } \\
\hline Genotypes & 54 & $313.49 *$ & $5.60^{*}$ & $28.01 *$ & $2.19 *$ & $3.83^{*}$ \\
\hline General combining ability (GCA) & 9 & $1741.57^{*}$ & $16.66^{*}$ & 76.04 & 11.88 & 13.5 \\
\hline Specific combining ability (SCA) & 45 & 27.87 & $3.39 *$ & 18.41 & 0.26 & $1.89^{*}$ \\
\hline Generation $\left(\mathrm{F}_{1}\right.$ and $\left.\mathrm{F}_{2}\right)$ & 1 & 17 & $1.46^{*}$ & $27103.6^{*}$ & $51815.53 *$ & $1646.23^{*}$ \\
\hline Genotypes x Generation & 54 & $18.12 *$ & $1.16^{*}$ & $19.81 *$ & $1.56^{*}$ & $1.89^{*}$ \\
\hline GCA x Generation & 9 & $10.23 *$ & $0.98 *$ & $46.74^{*}$ & $8.4^{*}$ & $6.16^{*}$ \\
\hline SCA x Generation & 45 & $19.70^{*}$ & $1.20^{*}$ & $14.43 *$ & $0.20 *$ & $1.04^{*}$ \\
\hline Error & 216 & 3.51 & $0.49 *$ & 0.15 & 0.0022 & 0.022 \\
\hline \multicolumn{7}{|c|}{ Individual analysis of parents and $\mathrm{F}_{1}$ hybrids } \\
\hline F hybrids & 54 & $162.52 *$ & $3.52 *$ & $0.56^{*}$ & $3.72 *$ & $5.52 *$ \\
\hline General combining ability (GCA) & 9 & $907.99 *$ & $8.28 *$ & $2.08 *$ & $20.13 *$ & $18.93 *$ \\
\hline Specific combining ability (SCA) & 45 & $13.42 *$ & $2.56^{*}$ & $0.25 *$ & $0.44 *$ & $2.84^{*}$ \\
\hline Error & 108 & 5.28 & 0.49 & 0.08 & 0.14 & 0.29 \\
\hline \multicolumn{7}{|c|}{ Individual analysis of parents and $\mathrm{F}_{2}$ hybrid combinations } \\
\hline $\mathrm{F}_{2}$ segregant combinations & 54 & $169.10^{*}$ & $3.25^{*}$ & $47.27 *$ & $0.03 *$ & $0.19^{*}$ \\
\hline General combining ability (GCA) & 9 & $843.81^{*}$ & $9.37 *$ & $120.70^{*}$ & $0.15^{*}$ & $0.73^{*}$ \\
\hline Specific combining ability (SCA) & 45 & $34.15^{*}$ & $2.02 *$ & $32.51 *$ & $0.01 *$ & $0.09^{*}$ \\
\hline Error & 108 & 8.14 & 0.84 & 7.55 & 0.001 & 0.02 \\
\hline \multicolumn{7}{|c|}{ Ranges and coefficients of variation (CV) } \\
\hline \multicolumn{7}{|l|}{ Parents } \\
\hline Minimum & & 32.5 & 7.0 & 3.56 & 27.5 & 3.63 \\
\hline Maximum & & 72.1 & 14.1 & 5.97 & 33.0 & 9.23 \\
\hline $\mathrm{CV}(\%)$ & & 2.38 & 7.25 & 3.21 & 2.28 & 10.26 \\
\hline \multicolumn{7}{|l|}{$F_{1}$ hybrids } \\
\hline Minimum & & 32.5 & 7.0 & 10.92 & 27.5 & 3.63 \\
\hline Maximum & & 74.75 & 14.1 & 43.17 & 33.1 & 9.94 \\
\hline $\mathrm{CV}(\%)$ & & 3.86 & 7.61 & 5.87 & 12.27 & 7.8 \\
\hline \multicolumn{7}{|l|}{$\mathrm{F}_{2}$ segregant combinations } \\
\hline Minimum & & 32.5 & 6.63 & 12.7 & 25.3 & 3.18 \\
\hline Maximum & & 75.47 & 14.1 & 36.55 & 33.0 & 10.25 \\
\hline CV (\%) & & 4.81 & 9.82 & 11.97 & 5.24 & 5.07 \\
\hline
\end{tabular}

*Significant at $5 \%$ probability by the F-test; d.f. = degrees of freedom; $\mathrm{PH}=$ plant height; $\mathrm{SP}=$ spikes per plant; $\mathrm{KS}=$ kernels per spike; $100-\mathrm{KW}=$ one hundred kernels weight; GYP = grain yield per plant.

The mean squares for GCA and SCA in the $\mathrm{F}_{1}$ generation were greater than those for the $\mathrm{F}_{2}$ generation for the $100-\mathrm{KW}$ and grain yield per plant. This fact can be attributed to the higher hybrid vigor in $\mathrm{F}_{1}$ than in the $\mathrm{F}_{2}$ generation. These results are similar to those observed in wheat by Sharma and Sain (2003) and by Sood et al. (2007) in flax. The lack of understanding of these mechanisms retards the progress in plant breeding due to inefficient selection. For all the traits evaluated, the mean square values for GCA were greater than those for SCA. This is related to a large contribution of additive gene effects in the control of the studied traits (Joshi et al., 2004; Kamaluddin et al., 2007).

The five AFLP primer combinations used in the molecular analysis generated a total of 182 polymorphic bands among the ten genotypes studied. The primer combination M- 
CAG/E-ACC produced the highest number of markers (66). In addition, the reduced number of monomorphic fragments obtained in this study expresses the high potential of genetic variability detection in wheat by AFLP markers, as reported by Corbellini et al. (2002) and Paczos-Grzeda (2004).

The genetic distances indicated the presence of variability among the ten parents used in the crosses, regardless of the data-morphological, molecular, and combined or pedigree markers (Figure 1). All dendrograms showed a good fit between the graphical representation of distances and their original matrices. The cophenetic correlation coefficients were high to intermediate in all the cases: $\mathrm{Dg}_{-}{ }_{\text {pedigree }}(0.98) ; \mathrm{Dg}_{\text {morphological }}(0.89) ; \mathrm{Dg}_{-}{ }_{\text {molecular AFLP }}(0.88)$, and Dg- ${ }_{\text {morphological }+ \text { AFLP }}(0.61)$, indicating that the data matrix are represented by the dendogram with efficiency. These results were similar to those obtained in oats (Benin et al., 2008) and wheat (Bertan et al., 2009). Only cophenetic correlation values above 0.80 indicated a good fit between the original distance matrices and graphical distances. The fit between the original matrices and graphical distances depends on the distribution of genetic variability among the tested genotypes (Viera et al., 2005). In some cases, the clustering structure of the evaluated genotypes does not meet the hierarchical assumption, and hence, another form of representation needs to be adopted, although dendrograms are the most recommended modes for displaying biological data (Everitt, 1993).
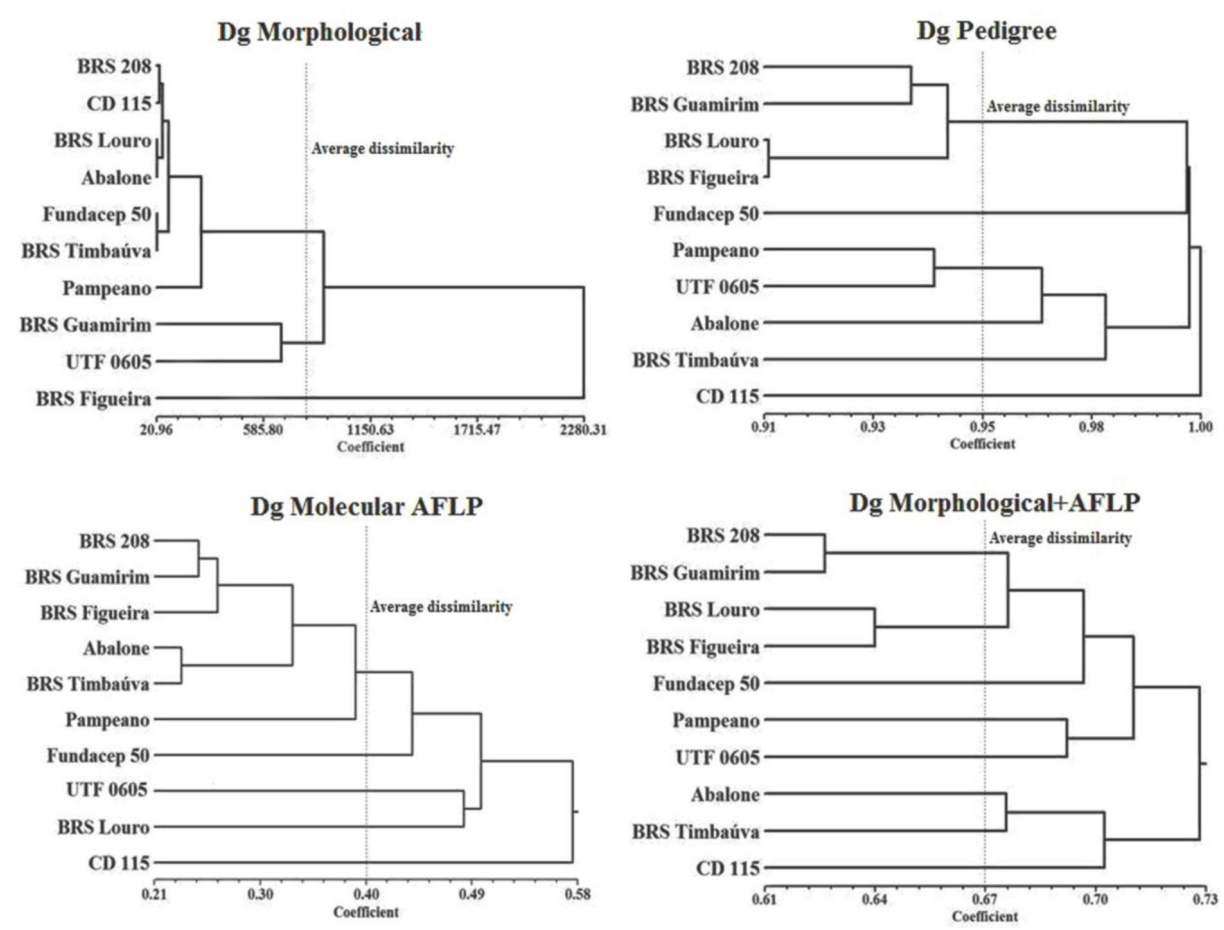

Figure 1. Dendrograms resulting from clustering analysis of 10 wheat genotypes obtained by the UPGMA using as genetic distance measure: $\mathrm{Dg}^{-}{ }_{\text {morphological }}=$ distance of Mahalanobis based on 5 morphological characters; Dg- $_{\text {pedigrec }}$ $=$ using the coefficient of Malécot; Dg- ${ }_{\text {molecular AFLP }}=$ polymorphism of AFLP markers (182 polymorphic bands) and $\mathrm{Dg}_{\text {morphological }+ \text { AFLP }}=$ based on the complement of Gower's genetic similarity index (Gower, 1971). The cophenetic correlation coefficients were $0.89,0.98,0.88$, and 0.61 for the four dendrograms, respectively. 
Highlighting the associations between the different estimates of genetic distance obtained is important (Table 3). Moderate associations were observed between Dg- ${ }_{\text {morphological }+ \text { AFLP }}$

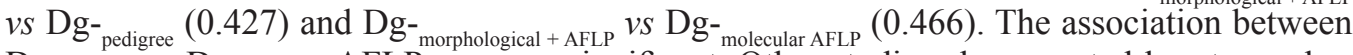
$\mathrm{Dg}_{\text {pedigree }_{-}} v s \mathrm{Dg}_{\text {- }_{\text {molecular }}}$ AFLP was non-significant. Other studies also reported low to moderate association between the genetic distances obtained using molecular markers and pedigree data (Almanza-Pinzón et al., 2003; Paczos-Grzeda, 2004). Correlations between molecular markers and pedigree data have varied widely depending on the organism and marker system used (Soleimani et al., 2007). The reason for these poor associations may be the background similarity found for unrelated accessions by using molecular markers (Graner et al., 1994) or by the selection pressure for different breeding objectives (Sun et al., 2003). The accuracy of the inbreeding coefficients depends partly on the availability of a comprehensive pedigree record for each cultivar (Soleimani et al., 2007; Bertan et al. 2009). The lack of complete information about the genealogy of some genotypes can also account for the lower precision of the estimates. Regarding the remaining associations (Table 3), the estimates have been shown to be based on distinct properties in assessing and representing genetic variability of tested genotypes.

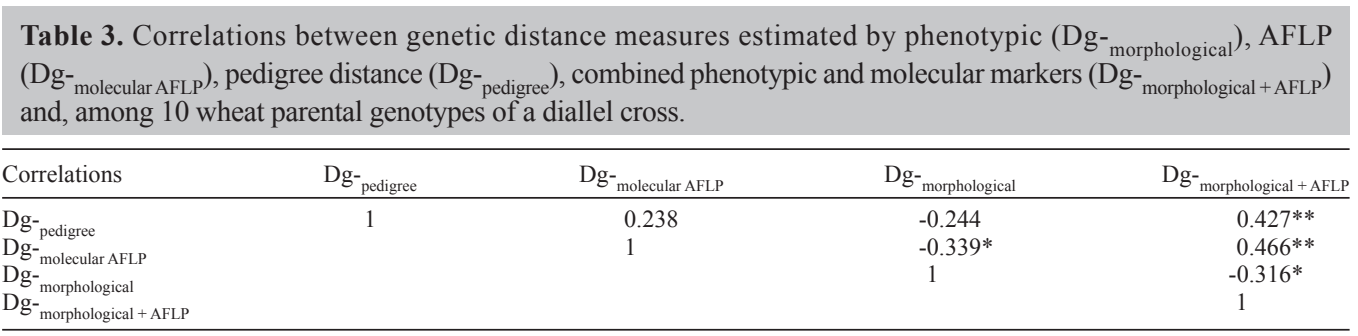

****Significant at 1 and 5\% probability, respectively, by the $t$-test.

For optimum genetic resource exploitation, parents should be derived from genetically divergent heterotic groups (Reif et al., 2003). Regarding the dendrogram obtained on the basis of $\mathrm{Dg}_{-}{ }_{\text {morphological }}$ the formation of three distinct clusters, the first formed by the most dissimilar genotype (BRS Figueira), the second formed by the genotypes BRS Guamirim and UTF 0605 , and the third formed by the remaining genotypes (Figure 1), can be noted. On the other hand, the dendrogram obtained on the basis of $\mathrm{Dg}_{-}{ }_{\text {molecular AFLP }}$ displayed 5 groups: group 1 formed by BRS 208, BRS Guamirim, BRS Figueira, Abalone, BRS Timbaúva, and Pampeano; and groups 2, 3, 4, and 5 formed by the genotypes Fundacep 50, UTF 0605, BRS Louro, and CD 115, respectively, forming individual groups. The groups formed in the dendrogram from Dg- ${ }_{\text {morphological }}$ were distinct from those formed in the dendrogram from Dg- ${ }_{\text {morphological }}$. This is confirmed by the negative correlation $(-0.339)$ between both the matrices (Table 3 ).

The negative correlation between $\mathrm{Dg}$ - $_{\text {morphological }} \times \mathrm{Dg}_{{ }_{\text {molecular AFLP }}}$ could be because of the wider genome sampling that molecular markers provide compared to the sampling obtained using the five morphological markers (Vieira et al., 2005; Bertan et al., 2009). The association between the estimates can also be influenced by the fact that a large portion of the variation detected by molecular markers was non-adaptive and hence not subject to either natural or artificial selection. Moreover, the variations detected by molecular markers were not subjected to environmental influence as observed for the morphological traits. Another explanation could 
be that 2 identical genotypes are always determined by the same genes, i.e., distinct genes can lead to a similar phenotype (Kuczyńska et al., 2007). However, a moderate positive correlation (0.47) was observed by Vieira et al. (2005) between the genetic distance estimates obtained using AFLP and morphological markers, suggesting that the association can depend on the genotypes tested and evaluation environment.

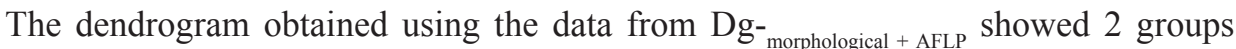
formed by more than 1 genotype, one formed by the genotypes BRS 208 and BRS Guamirim and another formed by BRS Louro and BRS Figueira. The remaining 6 genotypes were very distinct and did not cluster with any other genotype (Figure 1). Such clusters are consistent with the ones formed by the analysis with $\mathrm{Dg}_{-}{ }_{\text {molecular AFLP }}$ and can be confirmed by the significant association (0.466) between the matrices (Table 3 ). Other studies confirm that such techniques when used individually produce distinct results compared to a combined analysis (Bramardi et al., 2005). The negative correlation (-0.31) between the Dg- morphological + AFLP $_{\text {And the }}$ $\mathrm{Dg}_{\text {- }}$ morphological data could be due to the higher number of polymorphic bands (182) compared to the number of morphological traits evaluated.

The dendrogram obtained from the analysis of pedigree distances revealed two major groups, but no relationship was observed for the genotype CD 115 (Figure 1; Dg- ${ }_{\text {pedigree }}$ ). That is, a dissimilarity coefficient of 1 was found, indicating that no common parents were found in the other genotypes compared to CD 115. In addition, Fundacep 50 was distinct from the other genotypes. The remaining genotypes presented at least one commonality in their pedigrees, direct (parent) or through some common ancestral genotype (Table 1).

Selecting appropriate parental combinations that would yield superior hybrids is the most important aspect in hybrid breeding (Dreisigacker et al., 2005). A positive significant correlation was observed between the pedigree distance and SCA for traits KS $(0.45), 100-\mathrm{KW}(0.67)$ and GYP (0.62) in the $\mathrm{F}_{1}$ generation, the same occurred in the $\mathrm{F}_{2}$ generation with traits 100-KW $(0.62)$ and GYP (0.59) (Table 4). This suggests that increases in SCA occurred as a consequence of increases in pedigree distances. These associations could be successfully achieved because of a good pedigree record available for the parental genotypes used in the crosses (Table 1), resulting in prediction of more precise pedigree distances. Almanza-Pinzón et al. (2003) reported that pedigree distances provide a good estimation of genetic diversity when complete pedigrees are known and suggested that the coefficient of parentage should be the preferred method.

\begin{tabular}{|c|c|c|c|c|c|c|c|c|c|c|}
\hline \multirow[t]{3}{*}{ Correlations } & \multicolumn{10}{|c|}{ Specific combining ability } \\
\hline & \multicolumn{5}{|c|}{$\mathrm{F}_{1}$} & \multicolumn{5}{|c|}{$\mathrm{F}_{2}$} \\
\hline & $\mathrm{PH}$ & $\mathrm{SP}$ & KS & $100-\mathrm{KW}$ & GYP & $\mathrm{PH}$ & SP & KS & $100-\mathrm{KW}$ & GYP \\
\hline$D z$ & 0.05 & -0.23 & -0.17 & -0.37 & -0.21 & 0.10 & 0.37 & -0.36 & -0.35 & -0.33 \\
\hline Dg- & 0.33 & 0.35 & $0.45^{*}$ & $0.67 * *$ & $0.62 * *$ & 0.30 & -0.0 & 0.23 & $0.62 * *$ & 0.59 ** \\
\hline Dg- & 0.12 & 0.14 & -0.29 & $0.42 *$ & 0.01 & 0.07 & 0.19 & -0.17 & 0.35 & -0.10 \\
\hline $\begin{array}{l}\text { s molecular AFLP } \\
\text { Dg- }\end{array}$ & 0.01 & 0.15 & 0.16 & 0.36 & 0.12 & -0.04 & -0.36 & 0.05 & 0.38 & 0.14 \\
\hline
\end{tabular}

$* *, *$ Significant values at 1 and $5 \%$ probability, respectively, by the $t$-test for degrees of freedom -2 . For abbreviations, see Table 2. 
Similar results were obtained by Martin et al. (1995), who observed an association between $\mathrm{Dg}_{- \text {pedigree }}$ and heterosis in wheat hybrids for KW and protein content. Likewise, Perenzin et al. (1998) found significant pedigree distance effects on SCA for yield-related traits in the $F_{1}$ hybrids of bread wheat. However, some reports suggest that the inbreeding coefficient does not efficiently predict the hybrid performance (Almanza-Pinzón et al., 2003; Dreisigacker et al., 2005). The use of $\mathrm{Dg}_{-}{ }_{\text {molecular AFLP }}$ revealed a positive association of SCA of hybrids only with $100-\mathrm{KW}$; however, these results were only observed for the $\mathrm{F}_{1}$ generation $(0.42)$.

Despite these statistically significant associations ( $t$-test), the reduced absolute values require some caution in their application. In order to obtain a reliable and precise estimate of the genetic distance to be used by breeders, associations above $60 \%$ are needed. The lack of association between $\mathrm{Dg}_{-}{ }_{\text {molecular AFLP }}$ and the distance based on morphological traits suggests that although the AFLP markers were able to assess the genomic content of the evaluated genotypes (high polymorphism), this assessment was randomly distributed across functional and non-functional regions, which are not associated to the morphological traits evaluated in the present study.

The estimates of Dg- ${ }_{\text {morphological }}$ and Dg- ${ }_{\text {morphological }+ \text { AFLP }}$ did not show a significant association with the combining ability for the evaluated agronomical traits, neither in $\mathrm{F}_{1}$ nor in $\mathrm{F}_{2}$. The lack of correlation between $\mathrm{Dg}{ }_{\text {morphological }}$ and SCA can be due to the presence of complementary genes in some parents or due to a partial and insufficient representation of the genome when morphological data are used (Souza and Sorrells, 1991). According to Ghaderi et al. (1984), the absence of correlation can be attributed to additive gene effects for the traits and/or similar genes distributed between parents involved in the crosses, making the expression of SCA unpredictable and at random.

The lack of association between $\mathrm{Dg}^{-}{ }_{\text {morphological }+ \text { AFLP }}$ and hybrid performance may not be suitable for assessing the genetic differences between parents when $F_{1}$ heterosis and genetic variability needs to be maximized in the following generations. In wheat and other species, a few studies used molecular markers but were unable to define a clear relationship between molecular diversity and hybrid performance (Dias and Kageyama, 1997; Corbellini et al., 2002). Molecular markers that randomly assess the genome may have a limited application in parental selection, especially when they are used as the only source of information regarding the parents (Martin et al., 1995; Kotzamanidis et al., 2008). However, if markers associated with specific traits are selected, their use in estimating genetic dissimilarity and hence hybrid performance may be more efficient (El-Maghraby et al., 2005).

The prediction of hybrid performance by using different methods for estimating the genetic distance in wheat enables the characterization of genetic variability among parental genotypes. Any one of these methods could be used to study diversity and group genotypes, but none can be applied interchangeably. The choice of genetic diversity estimates depends largely on the tools available and how they fit into the breeding scheme (Fufa et al., 2005). Powell et al. (1996) studied the utility of AFLP, random-amplified polymorphic DNA, restriction fragment length polymorphism, and simple sequence repeats in soybean (Glycine max L. Merrill) and concluded that all four marker systems had different properties and different genetic relationships were derived from them.

A positive association between the pedigree genetic distance and trait weight of a $1000-\mathrm{KW}$ and grain yield per plant in the $\mathrm{F}_{1}$ and $\mathrm{F}_{2}$ generations indicates that this method should be considered in the selection of parents in wheat breeding programs. Furthermore, the understanding of hybrid performance and SCA and the identification of contrasting heterosis groups is important for conventional or hybrid wheat breeding programs. 


\section{REFERENCES}

Almanza-Pinzón MI, Khairallah M, Fox PN and Warburton ML (2003). Comparison of molecular markers and coefficients of parentage for the analysis of genetic diversity among spring bread wheat accessions. Euphytica 130: 77-86.

Barbosa-Neto JF, Sorrells ME and Cisar G (1996). Prediction of heterosis in wheat using coefficient of parentage and RFLP-based estimates of genetic relationship. Genome 39: 1142-1149.

Benin G, Carvalho FIF, Oliveira AC, Marchioro VS, et al. (2008). Morphological and AFLP markers for describing genetic relationships among white-oat genotypes. Bragantia 67: 563-568.

Bertan I, Carvalho FIF, Oliveira AC, Benin G, et al. (2009). Morphological, pedigree, and molecular distances and their association with hybrid wheat performance. Pesq. Agropec. Bras. 44: 155-163.

Bramardi SJ, Bernet GP, Asíns MJ and Carbonell EA (2005). Simultaneous agronomic and molecular characterization of genotypes via the generalized cluster analysis: an application to cucumber. Crop Sci. 45: 1603-1609.

Corbellini M, Perenzin M, Accerbi M, Vaccino P, et al. (2002). Genetic diversity in bread wheat, as revealed by coefficient of parentage and molecular markers, and its relationship to hybrid performance. Euphytica 123: 273-285.

Crossa J, Los Campos G, Pérez P, Gianola D, et al. (2010). Prediction of genetic values of quantitative traits in plant breeding using pedigree and molecular markers. Genetics 186: 713-724.

Cruz CD (2006). Programa Genes: Aplicativo Computacional em Genética e Estatística. UFV, Viçosa.

Dias LAS and Kageyama PY (1997). Multivariate genetic divergence and hibrid performance of cacao (Theobromacacao L.). Rev. Bras. Genet. 20: 63-70.

Dreisigacker S, Melchinger AE, Zhang P, Ammar K, et al. (2005). Hybrid performance and heterosis in spring bread wheat, and their relations to SSR-based genetic distances and coefficients of parentage. Euphytica 144: 51-59.

El-Maghraby MA, Moussa ME, Hana NS and Agrama HA (2005). Combining ability under drought stress relative to SSR diversity in common wheat. Euphytica 141: 301-308.

Everitt BS (1993). Cluster Analysis. Cambridge, University Press, London.

Franco J, Crossa J, Villasenor J, Taba S, et al. (1997). Classifying Mexican maize accessions using hierarchical and density search methods. Crop Sci. 37: 972-980.

Fufa H, Baenziger PS, Beecher BS, Dweikat I, et al. (2005). Comparison of phenotypic and molecular marker-based classifications of hard red winter wheat cultivars. Euphytica 154: 133-146.

Ghaderi A, Adams MW and Nassib AM (1984). Relationship between genetic distance and heterosis for yield and morphological traits in dry edible bean and faba bean. Crop Sci. 24: 37-42.

Gowda M, Kling CK, Wurschum T, Liu W, et al. (2010). Hybrid breeding in durum wheat: heterosis and combining ability. Crop Sci. 50: 2224-2230.

Gower JC (1971). A general coefficient of similarity and some of its properties. Biometrics 27: 857-874.

Graner A, Ludwig WF and Melchinger AE (1994). Relationships among European barley germplasm. II. Comparison of RFLP and pedigree data. Crop Sci. 34: 1199-1205.

Griffing B (1956). Concept of general and specific combining ability in relation to diallel crossing systems. Aust. J. Biol. Sci. 9: 463-493.

Joshi SK, Sharma SN, Singhania DL and Sain RS (2004). Combining ability in the $F_{1}$ and $F_{2}$ generations of diallel cross in hexaploid wheat (Triticum aestivum L. em. Thell). Hereditas 141: 115-121.

Kamaluddin RM, Singh LC, Prasad MZA and Joshi AK (2007). Combining ability analysis for grain filling duration and yield traits in spring wheat (Triticum aestivum L. em. Thell.). Genet. Mol. Biol. 30: 411-416.

Kotzamanidis ST, Lithourgidis AS, Mavromatis AG, Chasioti DI, et al. (2008). Prediction criteria of promising $\mathrm{F}_{3}$ populations in durum wheat: A comparative study. Field Crops Res. 107: 257-264.

Krystkowiak K, Adamski T, Surma M and Kaczmarek Z (2009). Relationship between phenotypic and genetic diversity of parental genotypes and the specific combining ability and heterosis effects in wheat (Triticum aestivum L.). Euphytica 165: 419-434.

Kuczyńska A, Surma M, Kaczmarek Z and Adamski T (2007). Relationship between phenotypic and genetic diversity of parental genotypes and the frequency of transgression effects in barley (Hordeum vulgare L.). Plant Breed. 126: 361-368.

Máric S, Laríc S, Artincic J, Pejíc I, et al. (2004). Genetic diversity of hexaploid wheat cultivars estimated by RAPD markers, morphological traits and coefficients of parentage. Plant Breed. 123: 366-369.

Martin JM, Talbert LE, Lanning SP and Blake NK (1995). Hybrid performance in wheat as related to parental diversity. Crop Sci. 35: 104-108.

May OL, Bowman DT and Calhoun DS (1995). Genetic diversity of U.S upland cotton cultivars released between 1980 and 1990. Crop Sci. 35: 1570-1574. 
Melchinger AE (1999). Genetic Diversity and Heterosis. In: The Genetics and Exploitation of Heterosis in Crops (Coors JG and Pandey S, eds.). ASA-CSSA, Madison, 99-117.

Mohammadi SA and Prasanna BM (2003). Analysis of genetic diversity in crop plants-salient statistical tools and considerations. Crop Sci. 43: 1235-1248.

Paczos-Grzeda E (2004). Pedigree, RAPD and simpliWed AFLP-based assessment of genetic relationships among Avena sativa L. varieties. Euphytica 138: 13-22.

Perenzin M, Corbellini M, Accerbi M, Vaccino P, et al. (1998). Bread wheat: $F_{1}$ hybrid performance and parental diversity estimates using molecular markers. Euphytica 100: 273-279.

Pillar VP (1997). Multivariate exploratory analysis and randomization testing using MULTIV. Coenoses 12: 45-148.

Powell W, Morgante M, Andre C, Hanafey M, et al. (1996). The comparison of RFLPs, RAPDs, AFLPs, and SSR (microsatellite) markers for germplasm analysis. Mol. Breed. 2: 225-238.

Reif JC, Melchinger AE, Xia XC, Warburton ML, et al. (2003). Use of SSRs for establishing heterotic groups in subtropical maize. Theor. Appl. Genet. 107: 947-957.

Rohlf FJ (2000). NTSYS-pc: Numerical Taxonomy and Multivariate Analysis System. Version 2.1. Exeter Software, New York.

SAS Institute (2002). Getting Started with the SAS Learning Edition. SAS Institute, Cary.

Sharma SN, Sain RS and Sharma RK (2003). Genetics of spike length in durum wheat. Euphytica 130: 155-161.

Soleimani VD, Baum BR and Johnson DA (2007). Analysis of genetic diversity in barley cultivars reveals incongruence between S-SAP, SNP and pedigree data. Genet. Resour. Crop. Evol. 54: 83-97.

Sood S, Kalia N, Bhateria S, Pathania A, et al. (2007). Inheritance of flower and seed colour in flax (Linum usitatissimum L.). Plant Breed. Genet. 32: 161-176.

Souza E and Sorrells ME (1991). Relationships among 70 North American oat germplasms. II. Cluster analysis using qualitative characters. Crop Sci. 31: 605-612.

Sun G, Bond M, Nass H, Martin R, et al. (2003). RAPD polymorphisms in spring wheat cultivars and lines with different level of Fusarium resistance. Theor. Appl. Genet. 106: 1059-1067.

Vieira EA, Carvalho FIF, Oliveira AC, Benin G, et al. (2005). Comparison among pedigree, morphological and molecular distance measures in oats (Avena sativa) in experiments with and without fungicide. Bragantia 64: 51-60.

Yadav HK, Shukla S and Singh PS (2007). Genetic divergence in parental genotypes and its relation with heterosis, $\mathrm{F}_{1}$ performance and general combining ability (GCA) in opium poppy (Papaver somniferum L.). Euphytica 157: 123130.

Yu CY, Hu SW, Zhao HX, Guo AG, et al. (2005). Genetic distances revealed by morphological characters, isozymes, proteins and RAPD markers and their relationships with hybrid performance in oilseed rape (Brassica napus L.). Theor. Appl. Genet. 110: 511-518. 